\title{
Generating Economic Growth: An Analytical Survey
}

\author{
Maria Thompson*
}

Department of Economics, NIPE, University of Minho, Portugal

\begin{abstract}
The theoretical richness and variety of the new growth literature can make it difficult to capture the essence of growth models. With this paper, we wish to provide one possible integrating view of the nature of the growth generating processes. Revisiting the models that constitute the core of growth theory, we expose analytically the main mechanisms through which long-run growth can be delivered.

Models that contemplate physical capital accumulation generate long-run growth through the attainment of a nondeclining marginal productivity of capital. One mechanism for achieving this entails the introduction of technological progress; another mechanism involves the inclusion of human capital accumulation; and a third method relies on the elimination from the production function of the diminishing returns to capital feature. The foundational models that classically represent each of these mechanisms are reviewed in an analytical and integrating perspective.
\end{abstract}

Some growth models do not contemplate physical capital and hence obtain long-run growth without generating a nondeclining marginal productivity of capital. We look into two reference models of this nature.

Keywords: Non-diminishing returns to capital, economic growth, research \& development, human capital accumulation, inada conditions. JEL classifications: $\mathrm{O} 3, \mathrm{O} 4$.

\section{INTRODUCTION}

The intense theoretical and empirical research that has characterized growth economics in the last three decades has resulted in a wide variety of growth models, each relying on specific assumptions and elaborate mathematical techniques, and consequently delivering growth predictions through several different mechanisms. This theoretical richness can make it difficult for newcomers in this research field to capture the essence of growth models.

With this paper, we wish to provide one possible integrating view of the nature of the growth generating mechanisms. We revisit the foundational models, upon which the numerous models that currently give body to growth theory are built. Our review is guided by the objective of exposing analytically, in an integrating perspective, the main mechanisms through which long-run growth can be delivered.

For models that contemplate physical capital accumulation, long-run growth is achieved whenever a non-declining marginal productivity of capital is generated. Hence, our main goal is to investigate analytically the mechanisms to endogenously generate a non-declining marginal productivity of capital.

Solow's [1] exogenous growth model obtains a nondeclining marginal productivity of capital through the means of sustained technological progress, with the rate of long-run per-capita growth given by the rate of technological progress. As it assumes that technological progress is an exogenous variable, Solow's model cannot explain within itself the

*Address correspondence to this author at the Department of Economics, NIPE, University of Minho, 4710-057 Braga, Portugal;

E-mail: mjthompson@eeg.uminho.pt factors that influence the rate of economic growth. The subsequent attempts to have the growth rate determined within the model gave rise to the endogenous or new growth theory.

As Solow [2] discusses, growth theory has so far produced three main mechanisms to generate economic growth through the attainment of a non-declining marginal productivity of capital. One mechanism, first developed by Romer $[3,4]$, entails introducing a theory of research and development (R\&D) into the growth model. The models in which endogenous technological progress is the engine of growth are identified as R\&D-based or idea-based growth models.

Another mechanism, introduced by Lucas [5], involves bringing into the model an endogenously determined accumulation of human capital as the source of growth. We name this type of models human capital-based growth models.

A third method to obtain long-run growth consists of eliminating from the production function one of the standard assumptions of the neoclassical model, more precisely the assumption of diminishing returns to capital. This was first experimented by Jones and Manuelli [6].

Through the analytical dissection of the above referred foundational models, we propose to expose the different growth generating mechanisms. In order to better distinguish these three main mechanisms, we adapt the models under review so that: (1) they all have a common production function, namely a Cobb-Douglas function with labouraugmenting productivity, and (2) they all assume a constant population.

Many growth models do not contemplate physical capital accumulation and hence, in them, economic growth does not require a non-declining marginal productivity of capital. The 
models by Grossman and Helpman [7] and Aghion and Howitt [8] constitute the foundations of R\&D-based models of this nature and we analyze them in a different section, as they do not follow the line of thought adopted for this analytical review, which is primarily aimed at investigating ways for endogenously obtaining economic growth via the generation of a non-declining marginal productivity of capital.

The paper is organized as follows. Section 2 reviews Solow's [1] model. Section 3 analyses Romer's [4] model. Section 4 studies Lucas' [5] model. Section 5 analyses the models by Jones and Manuelli's [6] and Barro and Sala-i-Martin's [9]. A discussion follows in Section 6. In Section 7, we complement our study with the analyses of the models by Grossman and Helpman [7] and Aghion and Howitt [8]. This analytical survey ends with Final Remarks.

\section{SOLOW'S MODEL}

In Solow's [1] model, technological progress generates a non-declining marginal productivity of capital and is the engine of long-run per-capita growth. The neoclassical model is set up for a closed economy with competitive markets and identical rational agents. The production function for output $Y(t)$ takes the labour-augmenting form ${ }^{1}$ :

$Y(t)=K(t)^{\alpha}(A(t) L(t))^{1-\alpha}, \quad 0<\alpha<1$,

where variable $A(t)$ represents the state of technology at time $t, K(t)$ is the capital stock, and $L(t)$ is the labour force, assumed to be equal to the economy's population.

With capital depreciation assumed to be zero, the capital accumulation equation is:

$$
\dot{K}(t)=Y(t)-C(t)
$$

Consumers' decisions are here specified according to the optimizing version of savings ${ }^{2}$ which means that the immortal representative consumer wishes to maximize, subject to a budget constraint, the present discounted value of the utilities of his/her present and future consumption streams:

$\max \int_{o}^{\infty} U(C(t)) e^{-\rho t} d t, \quad U(C(t))=\frac{C(t)^{1-\sigma}}{1-\sigma}$,

where variable $C(t)$ is aggregate consumption in period $t$, $\rho$ is the rate of time preference, and $\frac{1}{\sigma}$ is the elasticity of substitution between consumption at two periods of time. Most growth models use this constant relative risk aversion (CRRA) utility function in order to obtain a balanced growth path solution, i.e. in which the per-capita growth rate is constant in the long-run. They do this because, as pointed out by Barro and Sala-i-Martin [9], the result of a balanced growth path solution agrees with the empirical observation that

\footnotetext{
${ }^{1}$ As pointed out by Barro and Sala-i-Martin [9], technological progress must take the labour-augmenting form in the production function if models are to display a steady-state.

${ }^{2} \mathrm{~A}$ second branch of growth literature assumes that consumers save a fixed amount of output. We will analyse Solow's model with this alternative version of savings in Section 5.
}

many developed countries achieve per-capita growth rates which are positive and trendless for long periods of time.

The resource allocation problem faced by the social planner of this economy consists in maximizing the discounted utility function (2) subject to the budget constraint (1). This translates into maximizing the following currentvalue Hamiltonian $H(t)$ :

$H(t)=\frac{C(t)^{1-\sigma}}{1-\sigma}+\theta(t)\left[K(t)^{\alpha}(A(t) L(t))^{1-\alpha}-C(t)\right]$

The transversality condition to this problem is $\lim _{t \rightarrow \infty} e^{-\rho t} \theta(t) K(t)=0$. Log-differentiating the first-order condition, $\frac{d H(t)}{d C(t)}=0$, and combining it with the co-state condition, $\frac{d H(t)}{d K(t)}=\rho \theta(t)-\dot{\theta}(t)$, gives us the growth rate of consumption:

$g_{C}=\frac{1}{\sigma}\left[\alpha K^{\alpha-1}(A L)^{1-\alpha}-\rho\right]$

Equation (3) says that a balanced growth path solution, for which the growth rates of the three variables $K(t), \theta(t), C(t)$ are constant, requires a constant marginal productivity of capital (above the discount rate $\rho$ ), that is:

$\frac{d \log \left(\alpha K^{\alpha-1}(A L)^{1-\alpha}\right)}{d t}=0$

We will now look into Solow's model, firstly without technological progress and then with technological progress. In both situations we assume that the population is constant, which means that per-capita variables grow at the same rate as their aggregate counterparts.

Assuming first that technology is constant: With $g_{A}=0$, condition (4) implies that the growth rate of capital, $g_{K}$, is also zero. Then, log-differentiation of the production function tells us that the growth rate of output, $g_{Y}$, is also zero. Finally, equation (3) can be rewritten to give:

$\frac{Y}{K}=\frac{1}{\alpha} \frac{d Y}{d K}=\frac{C+\dot{K}}{K}=\frac{\sigma g_{C}+\rho}{\alpha}$,

which implies that, with $g_{K}=0$, the growth rate of consumption, $g_{C}$, must also equal zero. Concluding, the balanced growth path solution of Solow's model without technological progress is characterized by:

$g_{Y}=g_{C}=g_{K}=0$

This economy displays zero per-capita growth in the long-run because of diminishing returns to capital. In fact, with constant technology, $A$, the marginal productivity of capital, $\frac{d Y}{d K}=\frac{\alpha(A L)^{1-\alpha}}{K^{1-\alpha}}$, decreases as $K$ increases. As Lucas [5] writes, solving this optimization problem for its transitional dynamics would show that accumulation of capital will eventually drive its marginal productivity down until it equals $\rho$, which means that the economy reaches and stays 
in a steady-state level of capital for which the economy does not grow.

Assuming now that technology grows at a positive rate: With $g_{A}>0$, condition (4) implies that the growth rate of capital is equal to $g_{A}$. Log-differentiation of the production function tells us that the growth rate of output also equals $g_{A}$. Finally, equation (5) gives us the growth rate of consumption, equal to $g_{Y}$. Summing up, the balanced growth path solution of Solow's model with technological progress is characterized by ${ }^{3}$ :

$$
g_{Y}=g_{K}=g_{C}=g_{A}>0
$$

Concluding, when there is technological progress, longrun per-capita output grows at a positive rate. This happens because technological progress overcomes diminishing returns to capital. In fact, as $g_{K}=g_{A}$, the marginal productivity of capital is kept constant as $K$ increases, hence allowing for long-run growth. The root of sustained economic growth in Solow's model [1] has thus been identified.

In Solow's model, the preference parameters, $\sigma$ and $\rho$, and the technological parameter, $\alpha$, influence the steadystate value of the investment-output ratio, but do not affect the equilibrium growth rate. The only variable that influences the economic growth rate is the rate of technological progress, $g_{A}$, which is an exogenous variable to the model.

Given the exogenous nature of its engine of growth Solow's model cannot within itself explain how to influence the economic growth rate. The research activities aimed at determining the engine of growth within the model gave rise to the endogenous or new growth theory.

Endogenous growth models can be categorised in three groups. In one group, the source of sustained growth is endogenous technological progress which arises as a result of R\&D activities. A second group have endogenous human capital accumulation as their engine of growth. A third category of models generate economic growth via the elimination of the assumption of diminishing returns to physical capital.

\section{R\&D-BASED GROWTH MODELS}

In R\&D-based growth models, a theory of innovations is introduced in order to endogenously determine technological progress, the engine of economic growth. A decentralized theory of technological progress has innovations depending on intentional R\&D efforts and firms enjoying the exclusivity of their inventions through the use of patent rights. As the competitive framework no longer holds, growth models must incorporate imperfect competition. Representative of such models, we analyze Romer's [4] model, in the version presented by Jones [10] and by Aghion and Howitt [11].

${ }^{3}$ Barro and Sala-i-Martin [9] rewrite Solow's model in terms of consumption, capital and output per effective-labour, $\frac{C}{A L}, \frac{K}{A L}, \frac{Y}{A L}$, and analyse the transitional dynamics towards the steady-state of the model. They show that the system exhibits saddle-path stability.
On the preferences side, infinitely lived homogeneous consumers maximize the discounted value of the utility function (2), subject to a restriction that, in a closed economy, can be the following:

$\dot{B}(t)=r B(t)+w(t)-C(t)$,

where variable $B(t)$ stands for total assets, $r$ is the interest rate, $w(t)$ is the wage rate, and it is assumed that households provide one unit of labour per unit of time. The currentvalue Hamiltonian is:

$H(t)=\frac{C(t)^{1-\sigma}}{1-\sigma}+\theta(t)[r B(t)+w(t)-C(t)]$

The choice variable is $C(t)$, the state variable is $B(t)$, and the solution to this optimization problem has consumption growing at the constant rate $g_{C}$ given by the Euler equation:

$g_{C}=\frac{\dot{C}}{C}=\frac{1}{\sigma}(r-\rho)$

For the production side, Romer followed Ethier [12] in reinterpreting the utility function used by Dixit and Stiglitz [13] as a production function. In this reinterpretation, the final output is an increasing function of the total number of differentiated capital goods used by a final goods producer. Romer's model comprehends three productive sectors: the final good sector, the capital goods sector and the R\&D sector.

The final good, $Y$, is produced using as inputs labour devoted to final output, $L_{Y}$, and a number $A$ of differentiated durable capital goods, $i$, each produced in quantity $x_{i}$. All capital goods have additively separable effects on output:

$Y(t)=L_{Y}(t)^{1-\alpha} \int_{0}^{A(t)} x_{i}(t)^{\alpha} d i$

Capital accumulates according to equation (1) and, assuming that it takes one unit of foregone consumption to produce one unit of any type of capital good, $K$ is related to the capital goods according to the following rule:

$K(t)=\int_{0}^{A(t)} x_{i}(t) d i$

Total population is constant and any person can devote labour either to the final good sector, $L_{Y}$, or to the research sector, $L_{A}$. That is:

$\bar{L}(t)=L_{A}(t)+L_{Y}(t)$

Romer [4] specifies the process for accumulating new designs as:

$\dot{A}(t)=\delta L_{A}(t) A(t)$,

where $\delta$ is the research efficiency parameter. Equation (8) implies that devoting more labour to $R \& D$ leads to a higher rate of technological progress. It also means that the higher the total stock of knowledge, the higher the marginal produc- 
tivity of a researcher. Its third underlying assumption is that output of new designs is linear in $A$.

Continuing with the description of Romer's model, being in a perfect competition environment, in each period $t$, final good producers rent each capital good according to the profit maximization rule which gives the inverse demand curve faced by each capital good producer:

$$
R_{i}=\alpha L_{Y}^{1-\alpha} x_{i}^{\alpha-1}
$$

where $R_{i}$ is the rental price of each capital good. With given values of $r$ and $L_{Y}$, each capital good producer, who has already incurred the fixed cost investment in a design, $P_{A}$, and has the patent on it, will maximize its revenue minus variable cost at every date $t$ :

$\max \pi_{i}=R_{i} x_{i}-r x_{i}$

Profit maximization leads to the markup rule:

$$
R_{i}=\frac{r}{\alpha}
$$

The decision to enter the market and produce a new capital good depends on the comparison between the discounted stream of profits that the patent on this good will bring in the future, and the up front cost $P_{A}$ of the initial investment in a design. The market for designs is competitive so, at every date, the price for designs will be equalized to the present value of the future revenues that a monopolist can extract. The dynamic zero-profit/free-entry condition is:

$$
P_{A}(t)=\int_{t}^{+\infty} e^{-r(\tau-t)} \pi_{i}(\tau) d \tau,
$$

which, assuming that there are no bubbles, is equivalent to:

$$
\dot{P}_{A}(t)=r P_{A}(t)-\pi_{i}(t)
$$

The symmetry of the model implies that capital good producers charge the same price, $R_{i}=R$, and produce the same quantities, $x_{i}=x$, hence expression (9) is rewritten as:

$$
R=\alpha L_{Y}^{1-\alpha} x^{\alpha-1}
$$

Also, physical capital is equal to $K=A x$, and the production function can be rewritten as:

$Y=L_{Y}^{1-\alpha} A x^{\alpha}$

Solving the model for its balanced growth path, the Euler equation (6), says that the interest rate must be constant. Consequently so is $R$. Next, equation (8) tells us that a constant growth rate of $A$ requires $L_{A}$ to be constant. It follows from equation (7) that $L_{Y}$ must be constant too. Physical capital grows at the rate $g_{A}$ and $\log$-differentiation of the production function (12) shows that output also grows at the rate $g_{A}$. Finally, equation (1) says that $g_{C}=g_{K}$. With a constant population, this common growth rate is also the percapita growth rate. Summing up, the engine of growth in this model is technological progress:
$g=g_{C}=g_{Y}=g_{K}=g_{A}$

Notice that, rewriting the production function so that $K$ appears distinctively, we have:

$$
Y=L_{Y}^{1-\alpha}(A x)^{\alpha} A^{1-\alpha}=K^{\alpha}\left(L_{Y} A\right)^{1-\alpha}
$$

In this economy, as capital accumulates, the marginal productivity of capital, $\frac{d Y}{d K}=\frac{\alpha\left(L_{Y} A\right)^{1-\alpha}}{K^{1-\alpha}}$, is held constant, because $K$ and $A$ grow at the same rate. That is, technological progress overcomes diminishing returns to capital, thus making economic growth possible. The root of long-run percapita growth in Romer's model has hence been identified.

In Romer's model, the engine of growth, $g_{A}$, is endogenously determined. Equation (8) is essential for that determination. It implies that:

$g_{A}=\delta L_{A}$

Continuing with the determination of the equilibrium growth rate, we must now look at the labour market. The allocation of workers between the final output and research sectors obeys the equilibrium condition that remuneration of labour must be the same in both sectors. Such equilibrium condition, $\frac{d Y}{d L_{Y}}=\frac{d \dot{A}}{d L_{A}} P_{A}$, is equivalent to:

$P_{A}=\frac{(1-\alpha)}{\delta} L_{Y}^{-\alpha} x^{\alpha}$

Log-differentiating equation (14), rewriting the expression for profits as $\pi=(1-\alpha) R x$, and using expression (11), allows us to rewrite the zero-profit condition as:

$L_{Y}=\frac{r}{\delta \alpha}$

Equations (13) and (15) together give:

$g=\delta \bar{L}-\frac{r}{\alpha}$

The general equilibrium growth rate is the solution to the system of the two linear equations (6) and (16), in the two unknowns, $r$ and $g$. One curve is negatively sloped and the other is positively sloped, in the space $(r, g)$. The unique general equilibrium balanced growth path for this economy is ${ }^{4}$ :

$g=\frac{\alpha \delta \bar{L}-\rho}{\alpha+\sigma}$

Rivera-Batiz and Romer [15] point out that a parameter restriction is necessary for the equilibrium growth rate not to

\footnotetext{
${ }^{4}$ Arnold [14] provides a complete characterisation of the dynamics of Romer's model in the neighbourhood of its steady-state. He shows that the equilibrium of the model can be analysed in terms of a system of three differential equations in the three variables $\chi=\frac{C}{K}, Z=\frac{Y}{K}$, and $L_{Y}$. The steady-state of this system corresponds to the balanced growth path of Romer's model. Arnold shows that there is a unique and monotonic growth path converging to the steady-state, which is a saddle point. The initial value of $\frac{A}{K}$ uniquely determines the starting point on the saddle-path of the system.
} 
be greater than the interest rate, because, otherwise, present values would not be finite. This restriction is always met if $\sigma \geq 1$, which means that curve (6) lies on or above the $45^{\circ}$ line.

In Romer's model [4] the equilibrium growth rate is influenced positively by the technology parameters $\delta$ and $\alpha$, and negatively by the preference parameters $\sigma$ and $\rho$. Additionally, economic growth is proportional to the size of total population, $L$. This proportionality is called the scaleeffects prediction, which characterizes the first-generation of R\&D-based models ${ }^{5}$. It is a consequence of the way in which the equation for R\&D activities is specified. To see this point, let us look at Jones's [14] generalized specification for the invention of new designs:

$\dot{A}=\delta L_{A}^{\lambda} A^{\phi}$

According to equation (18), the marginal productivity of researchers varies with knowledge as:

$\frac{d\left(\frac{d \dot{A}}{d L_{A}}\right)}{d A}=\phi \lambda L_{A}^{\lambda-1} A^{\phi-1}$,

where the assumption $\phi<0$ represents negative external returns from the stock of knowledge in the innovation process, assumption $\phi>0$ implies positive external returns and the assumption $\phi=0$ means constant returns to scale.

Jones [14] argues that Romer's assumption of $\phi=1$ constitutes an arbitrary choice for the degree of increasing returns, and it is not empirically supported. However, if in Romer's model, instead of equation (8) we had:

$\dot{A}=\delta L_{A} A^{\eta} \quad, \quad \eta \neq 1$,

then Romer's model would not have a balanced growth path solution. That is, specification (8) is necessary for obtaining a balanced growth path.

The equilibrium growth rate in Romer's decentralized model is not optimal. There are two sources for this nonoptimality. The first is the fact that capital good producers charge a price that is higher than the marginal cost, $R=\frac{r}{\alpha}$. This implies that capital is remunerated by less than its marginal productivity, as $r=\alpha \frac{d Y}{d K}$. The second reason for the non-optimality of the decentralized economy is the presence of the externality generated by the fact that the individual decision to do R\&D does not take into account the fact that this research will benefit other R\&D activities via the creation of a larger stock of knowledge.

This concludes our analytical study of the first R\&Dbased growth model, representative of one of the main mechanisms to generate endogenous growth ${ }^{6}$.

${ }^{5}$ Jones [16] reviews the new literature on R\&D-based growth models that have eliminated the scale-effects prediction.

${ }^{6}$ As an example of a more recent $R \& D$-based growth model, we refer to one developed by Charles Jones in Aghion and Durlauf [17].
Two other major initial references in the literature on R\&D-based growth models are the models by Grossman and Helpman [7] and Aghion and Howitt [8]. These two models do not contemplate physical capital accumulation, hence in them, sustained per-capita growth does not require a constant marginal productivity of capital. The exposition of these two models in this Section would, therefore, break the line of thought adopted for this literature review whose main goal is to expose the three mechanisms to endogenously obtain a constant marginal productivity of capital and thus long-run per-capita growth. We review these two models in Section 7.

\section{HUMAN CAPITAL-BASED GROWTH MODELS}

Human capital-based growth models have human capital accumulation, rather than technological progress, as the engine of endogenous growth. Lucas' [5] model is the first of this kind. Lucas builds on Solow's model and introduces an equation for human capital accumulation, which allows for endogenous growth.

In Lucas' model, there are $L$ workers in total, with skill level $h$ ranging from zero to infinity. The amount of leisure is implicitly assumed to be fixed exogenously, hence each worker, who is endowed with one unit of time per unit of time, devotes the fraction $u(h)$ of his time to current production, and the remaining $1-u(h)$ to human capital accumulation. The effective workforce in production is then $L^{e}=\int_{0}^{\infty} u(h) L(h) h d h$. Assuming that all workers are identical, if they have the skill level $h$ and choose working time allocation $u$, then $L^{e}=u h L$.

In order to work with a production function common to all models reviewed in this paper, we adapt Lucas' [5] production function, specifying it as:

$Y(t)=K(t)^{\alpha}\left(A(t) L(t)^{e}\right)^{1-\alpha}$,

where the technology parameter $A$ and population $L$ are assumed constant.

Capital accumulates according to equation (1), and adopting Uzawa's [18] linear function, Lucas specifies the process for accumulating human capital as:

$\dot{h}(t)=h(t) \gamma(1-u(t))$,

where parameter $\gamma$ represents the efficiency of learning activities. This specification assumes that the accumulation of human capital is intensive in human capital, using no physical capital. Further, it allows for sustained per-capita growth at a constant rate because it does not display diminishing returns. This equation says that a balanced growth path solution requires a constant $u$.

The representative agent's problem is solved by choosing $C(t)$ and $u(t)$ that maximize the discounted utility (2) subject to restrictions (1) and (19). The current-value Hamiltonian $H(t)$ is:

$$
H=\frac{C^{1-\sigma}}{1-\sigma}+\theta_{1}\left[K^{\alpha}(A u h L)^{1-\alpha}-C\right]+\theta_{2}[h \gamma(1-u)]
$$


The four optimizing conditions, $\frac{d H}{d C}=0$, $\frac{d H}{d u}=0, \frac{d H}{d K}=\rho \theta_{1}-\dot{\theta}_{1}$ and $\frac{d H}{d h}=\rho \theta_{2}-\dot{\theta}_{2}$ lead to the following equations, respectively:

$$
\frac{\dot{C}}{C}=-\frac{1}{\sigma} \frac{\dot{\theta_{1}}}{\theta_{1}}
$$

$\theta_{1}(1-\alpha) A h L K^{\alpha}(A u h L)^{-\alpha}=\theta_{2} \gamma h$

$\frac{\dot{\theta_{1}}}{\theta_{1}}=\rho-\alpha K^{\alpha-1}(A u h L)^{1-\alpha}$

$\theta_{1}(1-\alpha) A u L K^{\alpha}(A u h L)^{-\alpha}+\theta_{2} \gamma(1-u)=\rho \theta_{2}-\dot{\theta}_{2}$

Solving the model for its balanced growth path, firstly, equations (20) and (22) together give:

$g_{C}=\frac{1}{\sigma}\left[\alpha K^{\alpha-1}(A u h L)^{1-\alpha}-\rho\right]$

Equation (24) implies that a constant $g_{C}$ requires a constant marginal productivity of physical capital, which in turn requires that $K$ grows at the same rate as $h$. Next, logdifferentiation of the production function tells us that output also grows at the same rate as human capital. Additionally, equation (1) ensures that consumption grows at the same rate as output and physical capital. These are per-capita growth rates, as $L$ is constant. Summing up, human capital growth is the engine of growth in this model:

$g=g_{Y}=g_{K}=g_{C}=g_{h}$

Concluding, Lucas' model overcomes diminishing returns to physical capital through the accumulation of human capital. Physical capital can be accumulated forever without decreasing its marginal productivity, $\frac{d Y}{d K}=\frac{\alpha(\operatorname{AuhL})^{1-\alpha}}{K^{1-\alpha}}$, because $K$ and $h$ grow at the same rate. The root of long-run percapita growth in Lucas' model has thus been exposed.

We must now finish solving of the model. Logdifferentiation of equation (21) gives:

$\frac{\dot{\theta_{1}}}{\theta_{1}}=\frac{\dot{\theta_{2}}}{\theta_{2}}$

Next, and as their first terms have much in common, equations (21) and (23) can be combined together to give:

$\frac{\dot{\theta_{2}}}{\theta_{2}}=\rho-\gamma$

Finally, equations (20), (25) and (26) together give us the equilibrium growth rate $^{7}$ :

${ }^{7}$ Xie [19] investigates the transitional dynamics of Lucas' model off its steady-state. Barro and Sala-i-Martin [9], too, analyse the transitional dynamics of Lucas' model. They show that the equilibrium of the model can be analysed in terms of a system of three differential equations in three variables, $\chi=\frac{C}{K}, W=\frac{K}{H}$, and $u$. The steady-state of this system corresponds to the balanced growth path of Lucas' economy and the system is saddle- $g=\frac{1}{\sigma}(\gamma-\rho)$

Lucas's model predicts that economic growth increases with the effectiveness of investment in human capital accumulation, $\gamma$. It also predicts that economic growth depends negatively on the preference parameters, $\rho$ and $\sigma$.

Notice that, like in Romer's [4], in this model the specification which is responsible for endogenous growth, equation (19), seems to have been designed in an arbitrary way, as Solow [2] argues. However, if in Lucas' model, such equation were to be replaced by:

$\dot{h}=h^{\lambda} \gamma(1-u) \quad, \quad \lambda \neq 1$,

the model would not deliver a balanced growth path solution. The growth rate would be eroding over time if $\lambda<1$, and would be explosive for $\lambda>1$. That is, specification (19) is necessary to achieve a balanced growth path.

We have now concluded our analysis of Lucas' [5] model, representative of the mechanism through which endogenous human capital accumulation overcomes diminishing returns to capital and thus delivers long-run per-capita growth $^{8}$.

Other major reference human capital-based models include Becker, Murphy and Tamura [21], Stokey [22] and Rebelo [23].

\section{MODELS WITHOUT DIMINISHING RETURNS TO CAPITAL}

In order to better expose the third mechanism for generating long-run per-capita growth, let us first recall the neoclassical model with no population growth. As studied in Section 2 , Solow's [1] basic proposition is that without technological progress, the effects of diminishing returns to capital will eventually drive the per-capita growth rate to zero. In fact, the aggregate production function of the neoclassical model, exhibits constant returns to scale and diminishing marginal productivity in each of the inputs. The concept of diminishing returns to capital is formally captured by the following assumptions:

$\frac{d Y}{d K}>0$ and $\frac{d^{2} Y}{d K^{2}}<0$ for all $K$,

and by the Inada conditions:

$\lim _{K \rightarrow \infty} \frac{d Y}{d K}=0$ and $\lim _{K \rightarrow 0} \frac{d Y}{d K}=\infty$

In this Section, for the capital accumulation specification, we adopt an alternative savings behavior according to which people save a constant proportion $s$ of gross income $Y$. Hence, depreciating at rate $d$, capital accumulates according to:

path stable, for $\sigma>\alpha$. Although they work with the original model, we find that our adapted Lucas' model will have the same behaviour.

${ }^{8}$ As an example of a more recent model that builds on Lucas's [5] framework, we refer to Farmer and Lahiri [20], who study a two-country version of such model with and without human capital externalities. 
$\dot{K}(t)=s Y(t)-d K(t)$

Diminishing returns to capital in Solow's model imply that its production function and, consequently, savings function are concave in the $(Y, K)$ space, which means that the depreciation line, $d K$, will eventually cross the savings function, $s Y$. When this happens, depreciation equals saving, and the economy is in a steady-state equilibrium with $K^{*}=A L\left[\frac{s}{d}\right]^{\frac{1}{1-\alpha}}$, and zero per-capita growth:

$s Y=d K \Rightarrow \dot{K}=0$

Concluding, diminishing returns to capital in Solow's model imply that the economy reaches a steady-state in which there is no economic growth.

The third mechanism to generate long-run per-capita growth arose with Jones and Manuelli [16], who introduce a production function without diminishing returns to capital.

In order to keep similarity with the previously discussed models, we modify Jones and Manuelli's production function, to become:

$Y(t)=v K(t)+K(t)^{\alpha}(A(t) L(t))^{1-\alpha}, \quad 0<\alpha<1$,

where $A(t)$ and $L(t)$ are constant. Such production function violates the first Inada condition, because:

$\lim _{K \rightarrow \infty} \frac{d Y}{d K}=v>0$

With capital accumulating according to equation (27), let us see how this changes the results of this model relative to that of Solow's. The savings function now tends asymptotically to the line $s v K$, in the $(Y, K)$ space. If this line is above the depreciation line, $d K$, then the depreciation function will never cross the savings function, meaning that this economy can sustain positive growth forever. That is:

$$
s v K>d K \Rightarrow \dot{K}>0
$$

The per-capita growth rate of capital is:

$\frac{\dot{k}}{k}=\frac{\dot{K}}{K}=\frac{s Y}{K}-d=s v+s \frac{(A L)^{1-\alpha}}{K^{1-\alpha}}-d$,

which means that as $K$ goes to infinity, the growth rate of capital equals $g_{k}=s v-d$. Hence, economic growth is possible for $s v>d$.

If, instead of a fixed savings rate, the model adopts the consumers optimizing behavior, then per-capita growth is given by $g=\frac{1}{\sigma}\left[\frac{d Y}{d K}-d-\rho\right]$, and economic growth is obtained for $v>d+\rho$.

We have thus verified how the elimination from the production function of the assumption of diminishing returns to capital generates long-run per-capita growth ${ }^{9}$.

${ }^{9}$ More recently, Jones, Manuelli and Siu [24] develop a stochastic version of the models described in Jones and Manuelli [6].
Barro and Sala-i-Martin [9] also present, in chapter 5, a model that eliminates diminishing returns to capital. They assume a constant returns to scale production function and a one-sector-framework in which output can be used for consumption, investment in physical capital and investment in human capital. For our earlier mentioned expositional purposes, we modify their production function, to become:

$Y(t)=K(t)^{\alpha}(A(t) H(t))^{1-\alpha}$,

where the technology parameter, $A(t)$, is constant and $H(t)=h(t) L(t)$ is the number of workers multiplied by their human capital, $h(t)$. As labour is constant, the growth of $H$ is solely due to the growth of $h$.

The budget constraint for this economy is:

$Y(t)=C(t)+I_{K}(t)+I_{H}(t)$,

and, with $d$ as the rate of depreciation for both physical and human capital, the investment equations are:

$\dot{K}(t)=I_{K}(t)-d K(t)$

$\dot{H}(t)=I_{H}(t)-d H(t)$,

Assuming that households are also producers, the current-value Hamiltonian for the representative agent's maximization problem, $J(t)$, is:

$J=\frac{C^{1-\sigma}}{1-\sigma}+u\left[I_{K}-d K\right]+v\left[I_{H}-d H\right]+$

$w\left[K^{\alpha}(A H)^{1-\alpha}-C-I_{K}-I_{H}\right]$,

where $u(t)$ and $v(t)$ are the current-values of physical capital and human capital accumulation respectively, and $w(t)$ is the Lagrangian multiplier associated with the budget constraint. The decision variables of this problem are $C(t)$, $I_{H}(t)$ and $I_{H}(t)$, and the state variables are $K(t)$ and $H(t)$.

The first-order conditions $\frac{d J}{d I_{K}}=0$ and $\frac{d J}{d I_{H}}=0$ tell us that $u=v=w$. The solution implies then that $\frac{\dot{u}}{u}=\frac{\dot{v}}{v}=\frac{\dot{w}}{w}$. This result together with the two co-state conditions, gives:

$\frac{K}{H}=\frac{\alpha}{1-\alpha}$,

which means that $g_{K}=g_{H}$. The equilibrium per-capita growth rate, is then obtained using the first-order condition, $\frac{d J}{d C}=0:$

$g=\frac{1}{\sigma}\left[A^{1-\alpha} \alpha^{\alpha}(1-\alpha)^{(1-\alpha)}-d-\rho\right]$

Output is equal to:

$Y=A^{1-\alpha}\left(\frac{1-\alpha}{\alpha}\right)^{1-\alpha} K=B K$,

where $B$ is a constant. Hence this model, too, generates economic growth via the elimination of the diminishing re- 
turns to physical capital assumption, obtained through a constant $\frac{K}{H}$ ratio.

This model, like the AK model, has no transitional dynamics. The growth rate is always given by equation (28).

The AK model constitutes the extreme case of a model that avoids the diminishing returns to scale assumption. It assumes that production exhibits exactly constant returns to scale to a broad concept of capital that includes all kinds of capital. Its production function, $Y=A K$, simply does not have the diminishing returns to capital property.

\section{DISCUSSION}

In the previous Sections, we have analyzed three alternative mechanisms for endogenously achieving a constant marginal productivity of capital and hence long-run percapita growth. The first mechanism relies on technological progress, the second relies on human capital accumulation and the third entails eliminating the assumption of diminishing returns to capital from the production function.

In their processes of generating economic growth, all the discussed endogenous growth models commence with a production function like $Y=K^{\alpha}(A L)^{1-\alpha}$, and arrive at a production function like $Y=B K$, where $B$, the marginal productivity of capital, is constant.

There is, however, a fundamental difference between both R\&D-based and human capital-based growth models and the third type of growth models studied: Beginning with Romer's [4] production function, discussed in Section 3:

$Y=L_{Y}^{1-\alpha} A x^{\alpha}=\frac{L_{Y}^{1-\alpha} A^{1-\alpha}}{K^{1-\alpha}} K=B K$,

where $B$ is constant because $L_{Y}$ is constant and $K$ grows at the same rate as $A$.

Next recall Lucas' [5] production function, studied in Section 4:

$Y=K^{\alpha}(A u h L)^{1-\alpha}=\frac{(A u L)^{1-\alpha} h^{1-\alpha}}{K^{1-\alpha}} K=B K$,

where $B$ is constant because $A, L$ and $u$ are constant and $K$ grows at the same rate as $h$.

With these two models, the function $Y=B K$ is obtained because diminishing returns to physical capital are overcome by either the progress of technology or the accumulation of human capital.

As opposed to these two types of growth model, in the third category of endogenous growth models, diminishing returns to physical capital are not overcome. They are eliminated. For instance, Barro and Sala-i-Martin's [9] production function, analyzed in Section 5, is:

$Y=A^{1-\alpha}\left(\frac{H}{K}\right)^{1-\alpha} K=A^{1-\alpha}\left(\frac{1-\alpha}{\alpha}\right)^{1-\alpha} K=B K$,

where $B$ is constant because the ratio $\frac{H}{K}$ is equal to the constant $\frac{1-\alpha}{\alpha}$, meaning that it is fixed by the exogenous technol- ogy parameter. In contrast, for example, in Romer's model, the ratio $\frac{K}{A}=L_{Y}\left[\frac{\alpha^{2}}{r}\right]^{\frac{1}{1-\alpha}}$ depends on the equilibrium values of $L_{Y}$ and $r$. That is, for each balanced growth path, there is a different $\frac{K}{A}$ ratio, which is constant because $g_{K}=g_{A}$.

\section{R\&D-BASED MODELS WITHOUT PHYSICAL CAPI- TAL}

We next analyze two other important initial contributions to endogenous growth theory, namely those by Grossman and Helpman's [7] and by Aghion and Howitt [8]. These models are R\&D-based growth models. They cannot be compared with the previously analyzed models, because they do not contemplate physical capital and hence, in them, economic growth does not require a non-declining marginal productivity of capital.

\section{GROSSMAN AND HELPMAN'S GROWTH MODEL}

In Grossman and Helpman's [7] model, growth is obtained through the production of differentiated consumer goods, which are increasing because of deliberate R\&D activities. In order to capture consumers' taste for variety, the authors build on Dixit and Stiglitz [13] in defining an index $D$ through a constant elasticity of substitution (CES) function:

$D(t)=\left[\int_{0}^{A(t)} x(t)_{j}^{\alpha} d j\right]^{\frac{1}{\alpha}}, \quad 0<\alpha<1$,

where $x_{j}(t)$ is the quantity of the differentiated good $j$, and $A(t)$ is the number of available brands. The elasticity of substitution between every pair of goods is $\frac{1}{1-\alpha}$. This function yields constant elasticity demand functions for each good. It implies that a doubling of each of the $x_{j}$, for given $A$, doubles the index $D$. The index increases with each of the $x_{j}$ individually, but at a non-increasing rate. A higher $\alpha$ means that the goods are better substitutes in consumption.

The price index of $D, p_{D}$, is given by:

$p_{D}(t)=\left[\int_{0}^{A(t)} p(t)_{j}^{-\frac{\alpha}{1-\alpha}} d j\right]^{-\frac{1-\alpha}{\alpha}}$

Assuming that, once invented, all brands require one unit of labour per unit of output, marginal cost equals the wage rate $w(t)$ for all brands. Then, assuming that the wage rate equals unity, the profit maximization problem of these monopolistic competitors leads to the markup rule: $p_{j}(t)=p(t)=\frac{1}{\alpha}$. With this price, profits are given by:

$\pi(t)=\frac{1-\alpha}{\alpha} \frac{X(t)}{A(t)}$

where $X(t)=A(t) x(t)$, represents aggregate output of differentiated goods.

Development of new varieties of goods requires an effort in $R \& D$. The $R \& D$ costs have to be paid up front, before 
profits are realized. The cost of inventing a new product is defined as:

$$
\frac{a w(t)}{A(t)}=\frac{a}{A(t)}
$$

where $a$ is a parameter and $A(t)$ represents the stock of knowledge, equal to the number of already invented goods. Notice that this specification introduces an externality into the model. When they create new goods, producers are increasing the level of knowledge, which lowers the cost of innovation for other producers.

A typical firm owns the patent on a differentiated good and enjoys indefinite monopoly power on its supply. The value of this firm is then equal to the present discounted value of its profits:

$$
v(t)=\int_{t}^{\infty} e^{-r(\tau-t)} \pi(\tau) d \tau,
$$

which is equivalent to:

$$
r(t)=\frac{\dot{v}(t)}{v(t)}+\frac{\pi(t)}{v(t)}
$$

The free-entry condition is, then:

$$
v(t)=\frac{a}{A(t)} \quad \text { if } \dot{A}>0
$$

Clearing of the labour market requires that employment in $\mathrm{R} \& \mathrm{D}, \frac{a}{A} A$, plus employment in manufacturing of the goods, $X$, must equal the total supply of labour, assumed constant:

$\frac{a}{A(t)} \dot{A}(t)+X(t)=\bar{L}(t)$

The symmetry of the model implies that the quantities of each good produced are the same, $x_{i}=x$. We can then evaluate the consumption index, $C$. Variable $C$ represents consumption in terms of index $D$. In equilibrium $C=D$. So:

$C=D=A^{\frac{1-\alpha}{\alpha}} X$

Equation (33) says that, as $L$ is constant, a balanced growth path solution, requires that $X$ is constant. Then, according to equation (34), the growth rate of $C$ is $g_{C}=\frac{1-\alpha}{\alpha} g_{A}$.

Now follows the determination of the equilibrium growth rate. With the help of equations (30) and (32), equation (31) is rewritten as:

$g_{C}=\frac{(1-\alpha)^{2}}{\alpha} \frac{L}{a}-(1-\alpha) r$

We assume the optimizing version of consumers behavior. Hence maximizing the discounted standard utility (2) subject to an intertemporal constraint leads the representative household to allocate consumption according to the following rule:
$g_{C}=\frac{1}{\sigma}\left(r-\rho-\frac{\dot{p_{D}}}{p_{D}}\right)$

Recall $p_{D}$. As $p_{j}=p$ for every good, it follows that $p_{D}=A^{-\frac{1-\alpha}{\alpha}} p$. Hence equation (36) can be rewritten as:

$g_{C}=\frac{1}{\sigma-1}(r-\rho)$

The equilibrium growth rate is determined by the system composed by the linear equations (35) and (37), in the two unknowns $r$ and $g_{C}$. The first equation is negatively sloped and the second is positively sloped in the space $\left(r, g_{C}\right)$. The unique equilibrium growth rate is:

$g=\frac{1-\alpha}{[\alpha+\sigma(1-\alpha)]}\left[\frac{1-\alpha}{\alpha} \frac{L}{a}-\rho\right]$

The equilibrium growth rate depends positively on the size of population $L$. This is the scale-effects prediction, mentioned earlier, that characterizes the first generation of R\&D-based growth models. Growth will also be higher, the higher the degree of monopoly $(1-\alpha)$. Growth also depends negatively on the value of $a$, as the cost of making an innovation is proportional to $a$. Finally, and as usual, the preference parameters $\rho$ and $\sigma$ influence economic growth negatively.

Grossman and Helpman's [7] specification of innovation cost, $\frac{a}{A}$, fits the labour market equilibrium condition (33) in a way such that it generates a constant growth rate. This cost specification can also be considered arbitrary, but the truth is that if, for instance, it were replaced by:

$\frac{a}{A^{\phi}} \quad, \quad \phi \neq 1$

this model would not deliver a balanced growth path solution.

\section{AGHION AND HOWITT'S GROWTH MODEL}

In Aghion and Howitt's [8] model, economic growth is generated by a random sequence of quality improving innovations that result from research activities, which are themselves uncertain. We analyze Aghion and Howitt's [11] version of their model.

This economy is populated by a continuous mass of individuals, $L$, equal to total labour supply, with linear intertemporal preferences, given by:

$U(y(t))=\int_{0}^{\infty} y(t) e^{-r t} d t$

where $r$ is the rate of time preference, equal to the interest rate.

The labour force produces capital goods in a one-to-one fashion. Capital goods are used to produce the final good, $y$, according to the following production function: 
$y(t)=A(t) x(t)^{\alpha} \quad, \quad 0<\alpha<1$,

where $x(t)$ is the quantity of capital goods in existence and $A(t)$ is the technology parameter.

Innovation consists of inventing a new intermediate good that, when successful, renders the old one obsolete and raises the technology parameter by a constant factor, $\gamma$ :

$$
\frac{A_{i+1}}{A_{i}}=\gamma>1 \text {, }
$$

where $i$ is the number of innovations that have occurred so far.

When the amount $n$ of labour is assigned to R\&D, innovations arrive randomly according to a Poisson process with arrival rate $\lambda n, \lambda>0$. Parameter $\lambda$ indicates the productivity of the research technology. This specification means that the probability of an innovation in a given unit of time is $\lambda n$.

The economy's total stock of labour is allocated between R\&D activities, $n(t)$, and the production of capital goods, $x(t)$. The labour market clearing condition is:

$$
L(t)=x(t)+n(t)
$$

The amount of labour allocated to research is determined by the following arbitrage condition:

$w_{i}=\lambda V_{i+1}$,

where $w_{i}$ is the wage rate and $V_{i+1}$ is the discounted expected payoff to the $(i+1) t h$ innovation. This condition means that in equilibrium a worker must be indifferent between an hour's work in manufacturing, $w_{i}$, and an hour's work in research. The value to a worker of an hour's work in research is equal to the flow probability of an innovation, $\lambda$, times the value of that innovation, $V_{i+1}$, as an hour's work in research after the ith innovation results in the $(i+1) t h$ innovation.

The value $V_{i+1}$ is determined by the following asset condition:

$r V_{i+1}=\pi_{i+1}-\lambda n_{i+1} V_{i+1}$

which says that the expected income generated by a patent on the $(i+1)$ th innovation during a unit time interval, $r V_{i+1}$, must be equal to the profit flow that the producer of the $(i+1)$ th innovation obtains, $\pi_{i+1}$, minus the expected loss that will occur when the next innovation replaces the $(i+1)$ th innovation. This expected loss is equal to the flow probability of the innovation occurring, $\lambda$, times the amount of labour dedicated to research after the $(i+1)$ th innovation, $n_{i+1}$, times the value that will be lost, $V_{i+1}$. This equation, rewritten, shows the effects of creative destruction. The higher the number of researchers after the $(i+1)$ th innovation, $n_{i+1}$, the smaller the payoff to innovating the $i t h$ good.
Let us move on to the specification of the profit flow, $\pi_{i}$, and of the flow demand for manufacturing labour, $x_{i}$. Final good production uses each capital good according to the profit maximization rule $\frac{d y}{d x_{i}}=p_{i}$ which, recalling the production function (38), leads to:

$x=\left(\frac{\alpha}{\frac{p_{i}}{A_{i}}}\right)^{\frac{1}{1-\alpha}}$

The intermediate good producer that uses the ith innovation can be thought as either the inventor and producer of the good $i$ or the producer who buys the patent at the price $V_{i}$. His maximisation problem is:

$\max \pi_{i}=p_{i} x-w_{i} x$,

and its solution entails the markup rule: $p_{i}=\frac{w_{i}}{\alpha}$. So, replacing $p_{i}$ in equation (41) gives us the required specification for $x_{i}$. It follows that $\pi_{i}$ is equal to:

$\pi_{i}=(1-\alpha) \alpha A_{i}\left(\frac{\alpha^{2}}{\frac{w_{i}}{A_{i}}}\right)^{\frac{\alpha}{1-\alpha}}$

Next, the arbitrage condition (40) can be rewritten in the following way:

$w_{i}=\lambda V_{i+1}=\lambda \frac{(1-\alpha) \alpha A_{i+1}\left(\frac{\alpha^{2}}{\frac{w_{i+1}}{A_{i+1}}}\right)^{\frac{\alpha}{1-\alpha}}}{r+\lambda n_{i+1}}$

Recalling that $\frac{A_{i+1}}{A_{i}}=\gamma$, the productivity-adjusted wage rate, $\omega_{i}=\frac{w_{i}}{A_{i}}$, is equal to:

$\omega_{i}=\frac{w_{i}}{A_{i}}=\lambda \frac{\gamma(1-\alpha) \alpha\left(\frac{\alpha^{2}}{\frac{w_{i+1}}{A_{i+1}}}\right)^{\frac{\alpha}{1-\alpha}}}{r+\lambda n_{i+1}}$

Defining $\Pi=\frac{\pi_{i+1}}{A_{i+1}}$, the new arbitrage condition is:

$\omega_{i}=\frac{\lambda \gamma \Pi\left(\omega_{i+1}\right)}{r+\lambda n_{i+1}}$

Finally, the labour market clearing condition can also be written as:

$L=n_{i}+\mathrm{X}\left(\omega_{i}\right)$

The balanced growth equilibrium is defined as a stationary solution with $\omega_{i}=\omega$ and $n_{i}=n$. This means that both $\omega$ and $n$ remain constant over time, so that $w, \pi$ and $y$ are all scaled up by the same $\gamma>1$ each time an invention occurs. The system to be solved is composed by equations (42) and (43) in the unknowns $\omega$ and $n$. In the space $(\omega, n)$, the arbitrage equation is downward sloping, while the labour market clearing equation is upward sloping. In order to determine the unique balanced growth path solution 
$\left(\omega^{*}, n^{*}\right)$, we must investigate $\Pi(\omega)$. Knowing that $\pi=\left(\frac{1-\alpha}{\alpha}\right) w x$, it follows that:

$\Pi=\frac{\pi}{A}=\left(\frac{1-\alpha}{\alpha}\right) \omega(L-n)$

Then, replacing $\Pi$ in equation (42), we obtain the equilibrium value of $n$ :

$n^{*}=\frac{\gamma \lambda\left(\frac{1-\alpha}{\alpha}\right) L-r}{\lambda\left[\frac{\alpha+\gamma(1-\alpha)}{\alpha}\right]}$

Knowing $n^{*}$, we can use the labour market clearing condition to implicitly derive the equilibrium value $\omega^{*}$.

Now follows the determination of the growth rate of the economy. In a steady-state, the flow of the final good, $y$, produced between innovations ith and $(i+1)$ th is $y_{i}=A_{i}\left(x^{*}\right)^{\alpha}$. This implies that $y_{i+1}=A_{i+1}\left(L-n^{*}\right)^{\alpha}$. Therefore, we have that:

$$
\frac{y_{i+1}}{y_{i}}=\frac{A_{i+1}}{A_{i}}=\gamma
$$

Equation (45) tells us that $\ln \left(y_{i}\right)$ increases by an amount equal to $\ln (\gamma)$ each time an innovation occurs. But, as the real time between two innovations is random, the time path of $\ln (y)$ is also a random step function, with the size of each step equal to $\ln (\gamma)>0$. Also the time interval between each step is exponentially distributed with parameter $\lambda n^{*}$. Taking a unit time interval between $t$ and $t+1$, we have:

$\ln y(t+1)=\ln y(t)+(\ln \gamma) \varepsilon(t)$,

where $\varepsilon(t)$ is the number of innovations between $t$ and $t+1$. As $\varepsilon(t)$ is distributed Poisson with parameter $\lambda n^{*}$, the average growth rate of output, $g$, is:

$g=E[\ln y(t+1)-\ln y(t)]=\lambda n^{*}(\ln \gamma)$

This R\&D-based growth model also carries the scaleeffects prediction. In fact, equation (44) says that a rise in $L$ increases $n^{*}$, and therefore increases $g$. Economic growth is also influenced positively by $\lambda$, the research productivity parameter, as it raises $n^{*}$. On the contrary, a rise in $r$ or in $\alpha$ influences $n^{*}$ negatively, and so decreases the equilibrium growth rate.

This model has three externalities, two positive and one negative. One positive externality arises from the fact that monopoly rents are smaller than the consumer surplus. The other positive externality is due to the fact that one invention makes possible the next invention. The negative externality results from the fact that a new invention replaces the previous one.

Like in the previously studied models, Aghion and Howitt's R\&D equation (39) can be considered arbitrary. It is however necessary to obtain a balanced growth path solu- tion, for if instead of specification (39) we had the example given in Solow [2]:

$A_{i+1}=A_{i}+\gamma$,

then we would have $Y(t+1)=Y(t)+\lambda n^{*} \gamma$, and hence the growth rate, $g=\frac{\lambda n^{*} \gamma}{Y}$ would not be constant.

We have now concluded the analyses of two R\&D-based growth models that endogenously deliver long-run per-capita growth without obtaining a non-declining marginal productivity of capital ${ }^{10}$.

\section{FINAL REMARKS}

We have reviewed the prototypical models of endogenous growth in its three branches according to the engine of growth.

Our purpose has been to expose analytically the main mechanisms to endogenously generate long-run growth. At the same time we have attempted to offer a both detailed and panoramic view of the set of models that constitute the core of growth literature.

Our line of thought developed around the classical growth theory's postulate that, for models that contemplate physical capital accumulation, economic growth is achieved when a non-declining marginal productivity of capital is obtained. Hence, with Solow's [1] model as our starting point, we have investigated the existing mechanisms to endogenously generate a constant marginal productivity of capital and hence long-run growth.

We analyzed Romer's [4] model, and the ways in which R\&D activities can be modeled in growth models, so as to become the source of economic growth. Then, with Lucas [5], we analyzed the modelling of human capital accumulation and its role as the engine of growth. In these two kinds of models, economic growth is made possible because the diminishing returns to capital are overcome, respectively, by technological progress and by human capital accumulation.

A third group of models generate sustained growth through the direct elimination from the production function of the assumption of diminishing returns to capital. Representative of this category of models, we reviewed the models by Jones and Manuelli [6] and by Barro and Sala-i-Martin [9].

We complemented our literature review with an analytical incursion into the models by Grossman and Helpman [7] and by Aghion and Howitt [8], which also constitute important contributions to growth theory. Like Romer's, these are R\&D-based growth models. However, these two models do not contemplate physical capital, hence they obtain economic growth without the need to achieve a non-declining marginal productivity of capital.

Growth theory has been rapidly expanding, both in its formal modelling and in its econometric techniques. It

\footnotetext{
${ }^{10}$ As examples of more recent models that build on Aghion and Howitt's [8], we refer to Aghion and Howitt [11], Howitt [25], and Howitt and MayerFoulkes [26].
} 
counts with an increasing variety of theoretical models and several methods with which these models can be tested empirically. The numerous models that today give body to growth theory are all built upon the foundational frameworks that have been analyzed in this literature review. Hence we believe that the proposed integrated analytical perspective over the main growth generating processes is of relevance for those wishing to work in growth.

\section{ACKNOWLEGEMENT}

Financial support from Fundaçao Ciencia e Tecnologia is thankfully acknowledged.

\section{REFERENCES}

[1] Solow RM. A contribution to the theory of economic growth. Quarterly J Econ 1956; 70: 65-94.

[2] Solow RM. Growth Theory: An Exposition. New York. Oxford University Press, 2000.

[3] Romer P. Growth based on increasing returns due to specialization. AEA Pap Proc 1987; 77(2): 56-62.

[4] Romer P. Endogenous technological change. J Political Econ 1990; (98): 71-102.

[5] Lucas RE Jr. On the Mechanics of Economic Development. J Monetary Econ 1988; 22: 3-42.

[6] Jones L, Manuelli R. A Convex Model of Equilibrium Growth: Theory and Policy Implications. J Political Econ 1990; 98: 100838.

[7] Grossman G, Helpman E. Innovation and growth in the global economy. Cambridge, Mass: MIT Press, 1991.

[8] Aghion P, Howitt P. A model of growth through creative destruction. Econometrica 1992; 60(2): 323-51.

[9] Barro RJ, Sala-i-Martin X. Economic growth. McGraw-Hill, Inc 1995.
[10] Jones C. R\&D-based models of economic growth. J Political Econ 1995; 103: 759-84.

[11] Aghion P, Howitt P. Endogenous Growth Theory. Cambridge Mass: MIT Press, 1998.

[12] Ethier W. National and international returns to scale in the modern theory of international trade. Am Econ Rev 1982; (72): 389-405.

[13] Dixit A, Stiglitz J. Monopolistic competition and optimum product diversity. Am Econ Rev 1977; (67): 297-308.

[14] Arnold L. Stability of the market equilibrium in Romer's model of endogenous technological change: a complete characterisation. J Macroecon 2000; 22 (1): 69-84.

[15] Rivera-Batiz L, Romer P. Economic integration and endogenous growth. Quarterly J Econ 1991; 106(2): 531-55.

[16] Jones C. Growth: with or without scale effects? AEA Pap Proc 1999; 89(2): 139-44.

[17] Jones C. Growth and Ideas. In: Aghion P, Durlauf S, Eds. Handbook of Economic Growth, ch.16. North-Holland 2005: 1063-1111.

[18] Uzawa H. Optimum technical change in an aggregative model of economic growth. Int Econ Revue 1965; 6: 18-31.

[19] Xie D. Divergence in economic performance: transitional dynamics with multiple equilibria. J Econ Theory 1994; 63: 97-112.

[20] Farmer R, Lahiri A. A two-country model of endogenous growth Revue Econ Dynamics 2005; 8: 68-88.

[21] Becker G, Murphy K, Tamura R. Human capital, fertility and economic growth. J Political Econ 1990; 98 (5) part II: 12-37.

[22] Stokey NL. Human capital, product quality and growth. Quarterly J Econ 1991; 106(2): 587-616.

[23] Rebelo S. Long-run policy analysis and long-run growth. J Political Econ 1991; 99 (31): 500-21.

[24] Jones L, Manuelli R, Siu H. Fluctuations in convex models of growth II: Business Cycle Properties. WPaper, 2005.

[25] Howitt P. Endogenous growth and cross-country income differences. Am Econ Rev 2000; 90: 829-46.

[26] Howitt P, Mayer-Foulkes D.: R\&D, Implementation and Stagnation: A Schumpeterian Theory of Convergence Clubs. NBER 2002; WP 9104.

This is an open access article distributed under the terms of the Creative Commons Attribution License (http://creativecommons.org/licenses/by/2.5/), which permits unrestrictive use, distribution, and reproduction in any medium, provided the original work is properly cited. 